\title{
RANCANG BANGUN MEMONITOR ARUS DAN TEGANGAN SERTA KECEPATAN MOTOR INDUKSI 3 FASA MENGGUNAKAN WEB BERBASIS ARDUINO DUE
}

\author{
Resnu Mauliyana Mukti Wilutomo, Teguh Yuwono \\ Program Studi Diploma III Teknik Elektro \\ Sekolah Vokasi Universitas Diponegoro
}

\begin{abstract}
Resnu Mauliyana Mukti Wilutomo, Teguh Yuwono, 3 phase induction motor must work well and safely. Many types of interference have the potential to interfere with motor performance or even damage the motor itself, including due to power instability which includes imbalance between phase voltages and more phase currents. Monitoring an industrial activity especially monitoring the protection system is very important, it is intended that the disturbance that occurs in the 3 phase induction motor can be analyzed for the value and type of interference. Rapid technological development requires a monitoring system that is practical, fast and accurate. Sensors installed on this device are current sensors, voltage sensors, and speed sensors. The read, current, voltage and speed will be used as input signals to Arduino using the ADC (Analog to Digital Converter) process, Arduino programming uses $C++$ language. ESP8266 wifi module) will upload the data from the ADC (Analog to Digital Converter) process to the database which is then displayed on the web using the available internet network. The web programming language used is PHP. This tool makes it easy to monitor a 3 phase induction motor because it can be done anytime and anywhere. There was a difference of $\pm 0.24 A$ between the Tang Ampere measuring instrument and reading on the web. A $\pm 4 \mathrm{~V}$ difference occurs between the Multimeter measuring instrument with readings on the Web. The maximum speed of the 3-phase induction motor with no load is 22Rpm between the tachometer gauge and the web display.
\end{abstract}

Keywords: voltage sensor, current sensor, speed sensor, $C++$ language programming, PHP.

\section{PENDAHULUAN}

Latar Belakang

Motor induksi 3 fasa harus bekerja dengan baik dan aman. Banyak jenis gangguan yang berpotensi mengganggu kinerja motor atau bahkan merusak motor itu sendiri, diantaranya karena ketidakstabilan daya yang meliputi ketidakseimbangan tegangan antar fasa dan arus fasa lebih. Memonitor aktifitas industri khususnya memonitor gangguan pada motor induksi 3 fasa sangat penting, hal ini bertujuan agar gangguan yang terjadi pada motor induksi 3 fasa dapat di analisa nilai dan jenis gangguannya.

Teknologi yang berkembang sangat pesat menuntut suatu sistem memonitor yang praktis, cepat dan akurat. Memonitor aktifitas industri khususnya memonitor gangguan pada motor induksi 3 fasa memerlukan fasilitas memonitor dari jarak jauh, karena pada industri yang besar pasti banyak menggunakan motor induksi 3 fasa sebagai penggeraknya, sehingga memudahkan untuk memonitor gangguan yang terjadi. Internet menjadi solusi yang mudah, murah, dan cepat.

Sistem memonitor arus, tegangan dan kecepatan pada motor induksi 3 fasa menggunakan tampilan web dengan Arduino Due sebagai pengendali masukan dan keluaran menjadi solusi yang praktis, cepat dan akurat karena proses memonitor bisa dilakukan dimana saja dan kapan saja.

\section{Permasalahan}

Permasalahannya adalah sebagai berikut:

- Sensor Tegangan Yang Digunakan Adalah Rangkaian Pembagi Tegangan.

- Sensor Arus Yang Digunakan Adalah ACS712$5 \mathrm{~A}$

- Sensor Kecepatan Yang Digunakan Adalah Optocoupler

- Prinsip Kerja Arduino Due Dalam Mengolah Masukan Sensor Tegangan, Sensor Arus Dan Sensor Kecepatan Sehingga Bisa Menampilkan Nilai Pembacaan Pada Web.

- Pemrograman Web Yang Digunakan Adalah PHP.

- Perancangan Alat Ini Tidak Mencakup Pembahasan Secara Mendalam Rangkaian Dasar Arduino

\section{Motor Induksi 3 Fasa}

Motor listrik adalah suatu mesin listrik yang mengubah energi listrik menjadi energi gerak menggunakan gandengan medan listrik dan mempunyai slip antara medan stator dan medan rotor. Stator adalah bagian dari mesin yang tidak berputar dan terletak pada bagian luar. Stator terbuat dari besi bundar berleminasi dan mempunyai alur - alur sebagai tempat meletakan kumparan. Rotor adalah bagian dari mesin yang berputar bebas dan letaknya bagian dalam. Rotor terbuat dari besi leminasi yang mempunyai slot batang alumunium/ tembaga yang terhubung singkat pada ujungnya ${ }^{[4]}$. 
Motor induksi memiliki beberapa prinsip kerja motor induksi ${ }^{[4]}$ :

- Apabila sumber tegangan 3 fasa dipasang pada kumparan medan stator, timbullah medan $\operatorname{putar}^{[4]}$.

- Medan putar stator tersebut akan memotong batang konduktor pada rotor ${ }^{[4]}$.

- Akibatnya,pada kumparan jangkar (rotor) timbil tegangan induksi (ggl) ${ }^{[4]}$.

- Karena kumparan jangkar merupakan rangkaian tertutup ,ggl (E) akan menghasilkan arus (I) ${ }^{[4]}$.

- Adanya arus (I) di dalam medan magnet menimbulkan gaya $(\mathrm{F})$ pada rotor ${ }^{[4]}$.

- $\quad$ Bila kopel mula yang dihasilkan oleh gaya $(\mathrm{F})$ pada rotor cukup besar untuk memikul kopel poros, rotor akan berputar searah dengan medan putar stator $^{[4]}$.

\section{Arduino Due}

Arduino Due sesuai gambar 1 adalah varian papan pengembang mikrokontroler Arduino yang menggunakan CPU Atmel SAM3X8E ARM CortexM3. Dengan demikian, Arduino Due adalah Arduino Development Board pertama yang didasarkan pada mikrokontroler ARM 32-bit. Papan pengembang ini memiliki pin masukan/keluaran digital sebanyak 54 pin (12 di antaranya berkemampuan PWM), 12 pin masukan analog, 4 UART / hardware serial port, pencacah-waktu / clock berfrekuensi $84 \mathrm{MHz}$, koneksi dengan kemampuan USB OTG, 2 DAC (digital-to-analog converter), 2 TWI (Two Wire Interface, kompatibel dengan protokol I2C dari Phillips), soket jack catu daya standar $(5,5 / 2,1 \mathrm{~mm})$, konektor SPI header, konektor JTAG header, tombol reset, dan sebuah tombol hapus (erase button) ${ }^{[5]}$.

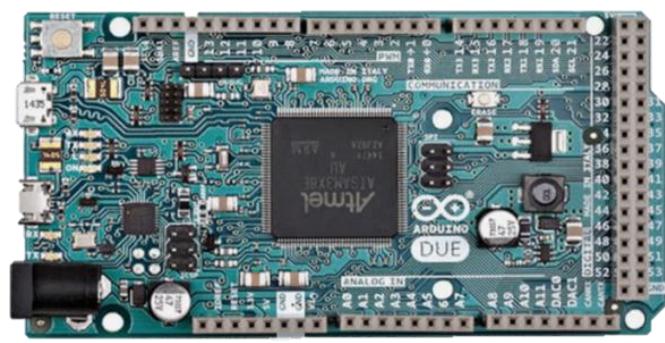

Gambar 1. Board Arduino due $e^{[5]}$

\section{Sensor Tegangan}

Sensor tegangan ini digunakan untuk mendapatkan nilai tegangan antar fasa sehingga dapat mengetahui besar tegangan fasa-fasa. Pada pembuatan sensor tegangan ini menggunakan transformator step down ,rangkaian penyearah, dan rangkaian pembagi tegangan ${ }^{[1]}$.

Rangkaian sensor tegangan pada prinsipnya yaitu melakukan pencuplikan tegangan yang mengalir masuk ke sistem pengukuran, cara kerja sensor tegangan ini yaitu sensor tegangan diletakan paralel terhadap jaringan sumber. Rangkaian ini pada initinya terdiri dari transformator step down berfungsi menurunkan tegangan, rangkaian penyearah,filter kapasitor, rangkaian pembagi tegangan ${ }^{[1]}$.

\section{Sensor Arus}

Sensor arus ini mengunakan ACS712-5A yang memiliki kemampuan arus sampai 5 Ampere. Keluaran dari ACS ACS712-5A adalah tegangan DC. Perubahan yang dihasilkan dari keluaran sensor arus ACS ACS712-5A ini sangat kecil sekitar $100 \mathrm{mV}$ setiap perubahan 1 Ampere (sesuai data sheet) ${ }^{[1]}$.

Sensor arus ini adalah salah satu produk dari allegro untuk solusi ekonomis dan presisi dalam pengukuran arus AC maupun DC. Sensor ini memiliki presisi, low-offset, dan rangkaian sensor linier hall dengan konduksi tembaga yang ditempatkan dengan permukaan dari aliran arus yang disensor. Ketika arus mengalir pada permukaan konduktor maka akan menghasilkan medan magnet yang dirasakan oleh IC hall efect yang terintegrasi kemudian oleh piranti tersebut dapat dirubah ke tegangan. Sensor ini memungkinkan untuk tidak menggunakan optoisolator karena antara terminal input arus dengan keluarannya sudah terisolasi secara kelistrikannya $^{[1]}$.

\section{Sensor Kecepatan}

Sensor kecepatan sesuai gambar 2 yang digunakan pada sistem ini adalah sensor optocoupler. Prinsipnya kerja sensor Optocoupler dengan kombinasi LED-Phototransistor adalah Optocoupler yang terdiri dari sebuah komponen LED (Light Emitting Diode) yang memancarkan cahaya infra merah (IR LED) dan sebuah komponen semikonduktor yang peka terhadap cahaya (Phototransistor) sebagai bagian yang digunakan untuk mendeteksi cahaya infra merah yang dipancarkan oleh IR LED ${ }^{[6]}$.

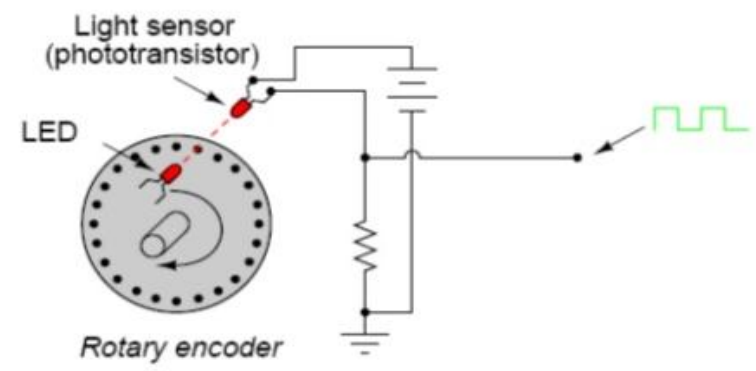

Gambar 2. Sensor optocoupler ${ }^{[7]}$

Optocoupler terdiri dari dua bagian yaitu ${ }^{[8]}$ : Pada transmitter dibangun dari sebuah LED infra merah. LED infra merah memiliki ketahanan yang lebih baik terhadap sinyal tampak. Cahaya yang dipancarkan oleh LED infra merah tidak terlihat oleh mata telanjang ${ }^{[8]}$. Pada bagian receiver dibangun dengan dasar komponen phototransistor. Phototransistor merupakan suatu transistor yang peka terhadap tenaga cahaya unruk menagkap radiasi dari sinar infra merah ${ }^{[8]}$. 


\section{Modul Wifi Arduino ESP8266}

ESP8266 sesuai gambar 3 merupakan modul wifi yang berfungsi sebagai perangkat tambahan mikrokontroler seperti Arduino agar dapat terhubung langsung dengan wifi dan membuat koneksi $\mathrm{TCP} / \mathrm{IP}^{[9]}$

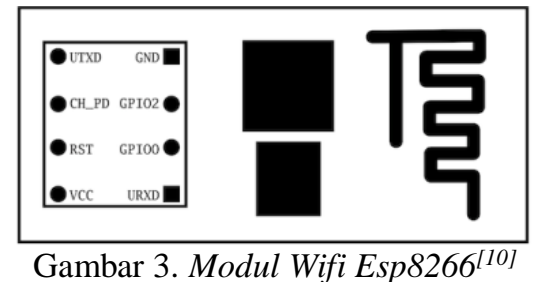

Modul ini membutuhkan daya sekitar $3.3 \mathrm{v}$ dengan memiliki tiga mode wifi yaitu Station, Access Point dan Both (Keduanya). Modul ini juga dilengkapi dengan prosesor, memori dan GPIO dimana jumlah pin bergantung dengan jenis ESP8266 yang kita gunakan. Sehingga modul ini bisa berdiri sendiri tanpa menggunakan mikrokontroler apapun karena sudah memiliki perlengkapan layaknya mikrokontroler ${ }^{[9]}$.

\section{Pengertian Web}

Jika mengamati situs-situs yang ada di internet, maka akan terlihat bahwa halaman web yang ditampilkan bukan hanya halaman yang statis. Halaman-halaman web yang dinamis ini tidak mungkin dibuat dengan menggunakan perintah HTML. Untuk membuat situs yang dinamis diperlukan kemampuan pemrograman web. Banyak sekali bahasa pemrograman web pada sisi server. Salah satu pemrograan sisi server yang paling banyak digunakan adalah $\mathrm{PHP}^{[11]}$. Website adalah keseluruhan halaman-halaman web yang terdapat dalam sebuah domain yang mengandung informasi. Sebuah website biasanya dibangun atas banyak halaman web yang saling berhubungan. Jadi dapat dikatakan bahwa, website adalah kumpulan halamanhalaman yang digunakan untuk menampilkan informasi teks, gambar diam atau gerak, animasi, suara, dan atau gabungan dari semuanya, baik yang bersifat statis maupun dinamis yang membentuk satu rangkaian bangunan yang saling terkait, yang masingmasing dihubungkan dengan jaringan-jaringan halaman ${ }^{[12]}$. Hubungan antara satu halaman website dengan halaman website lainnya disebut dengan hyperlink, sedangkan teks yang dijadikan media penghubung disebut hypertext ${ }^{[12]}$.

\section{PHP}

PHP adalah kependekan dari PHP Hypertext Preprocessor, bahasa interpreter yang mempunyai kemiripan dengan bahasa $\mathrm{C}++$ yang mempunyai kesederhanaan dalam perintah, yang digunakan untuk pembuatan aplikasi $w e b^{[12]}$

\section{HTML}

HTML (Hyper Text Markup Language) adalah sebuah bahasa pemrograman atau file teks yang berisi tag-tag markup yang berguna untuk memberitahukan browser bagaimana harus menampilkan sebuah halaman web. Sebuah file HTML harus memiliki ekstensi htm atau html. HTML merupakan bahasa standar yang digunakan oleh browser internet untuk membuat halaman dan dokumen pada sebuah web yang kemudian dapat diakses dan dibaca layaknya sebuah artikel. HTML juga dapat digunakan sebagai link antara file-file dalam situs atau dalam komputer dengan menggunakan localhost, atau link yang menghubungkan antar situs dalam dunia internet ${ }^{[11]}$. HTML (Hypertext Markup Language) merupakan standar bahasa yang digunakan untuk menampilkan dokumen web, yang bisa dilakukan dengan HTML yaitu $^{[11]}$ :

- Mengontrol tampilan dari web page dan content $^{[11]}$

- Mempublikasikan dokumen secara online sehingga bisa diakses dari seluruh dunia ${ }^{[11]}$.

- Membuat online form yang bisa digunakan untuk menangani pendaftaran, transaksi secara online $\mathrm{e}^{[11]}$.

- Menambahkan objek-objek seperti image, audio, video dan juga java applet dalam dokumen HTML ${ }^{[11]}$.

\section{CSS}

Cascading Style Sheets merupakan salah satu bahasa pemrograman web yang digunakan untuk mengendalikan beberapa komponen dalam sebuah $w e b$ agar lebih terstruktur dan seragam. Sama halnya styles dalam aplikasi pengolahan kata seperti Microsoft Word yang dapat mengatur beberapa style, misalnya : heading, subbab, bodytext, footer, images dan style lainnya untuk dapat digunakan bersamasama dalam beberapa berkas (file $)^{[11]}$. Pada umumnya CSS dipakai untuk memformat tampilan halaman web yang dibuat dengan bahasa HTML dan XHTML. CSS dapat mengendalikan ukuran gambar, warna bagian tubuh pada teks, warna tabel, ukuran border, warna border, warna hyperlink, warna mouse over, spasi antar paragraf, spasi antar teks, margin kiri, kanan, atas, bawah, dan parameter lainnya. CSS dapat didefiniskan juga sebagai bahasa style sheet yang digunakan untuk mengatur tampilan dokumen. Dengan adanya CSS memungkinkan untuk menampilkan halaman yang sama dengan format yang berbeda ${ }^{[11]}$.

\section{Basis Data}

Basis Data terdiri atas 2 kata, yaitu Basis dan Data. Basis kurang lebih dapat diartikan sebagai markas atau gudang, tempat bersarang atau 
berkumpul. Sedangkan Data adalah representasi fakta dunia nyata yang mewakili suatu objek seperti manusia, barang, hewan, peristiwa, konsep, dan sebagainya, yang diwujudkan dalam bentuk angka, huruf, symbol, teks, gambar, bunyi, atau kombinasinya. Basis data sesungguhnya memiliki prinsip kerja dan tujuan. Prinsip utamanya adalah pengaturan data/arsip. Dan tujuan utamanya adalah kemudahan dan kecepatan dalam pengambilan kembali data/arsip. Untuk mengolah basis data pada sistem yang penulis bangun, penulis menggunakan MySQL yang menggunakan bahasa SQL (Structured Query Language) yang secara khusus digunakan dalam pemrograman dan desain untuk menangani penyimpanan data pada $M y(\mathrm{RDBMS})^{[13]}$.

\section{Bahasa Basis Data}

Bahasa basis data terdiri atas sejumlah perintah (statement) yang di formulasikan dan dapat diberikan user dan dikenali/diproses oleh DBMS untuk melakukan aksi tertentu Sebuah bahasa basis data biasanya dapat dipilah kedalam dua bentuk yaitu $^{[13]}$ :

\section{- DDL (Data Definition Language)}

- DDL merupakan perintah SQL yang berhubungan dengan pendefinisian suatu struktur database, dalam hal ini database dan tabel. Perintah SQL yang termasuk dalam DDL adalah CREATE, ALTER, RENAME, DROP ${ }^{[13]}$.

- DML (Data Manipulation Language)

- DML merupakan perintah SQL yang berhubungan dengan manipulasi atau pengolahan data atau record dalam tabel. Perintah SQL yang termasuk dalam DML adalah SELECT, INSERT, UPDATE, $\operatorname{DELETE}^{[13]}$.

\section{MySQL}

MySQL merupakan salah satu database server yang berkembang di lingkungan open source dan didistribusikan secara gratis dibawah lisensi $\mathrm{GPL}^{[13]}$.

\section{PERANCANGAN SISTEM}

Blok Diagram Sistem sesuai gambar 4.

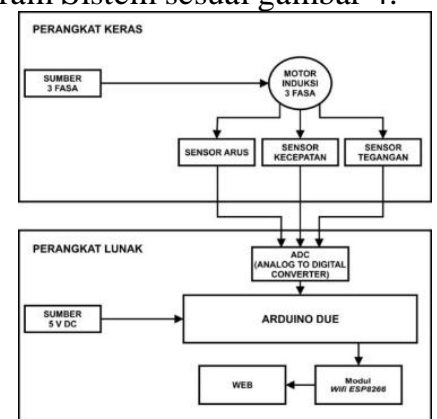

Gambar 4. Diagram blok sistem

\section{Rangkaian Sensor Tegangan}

Rangkaian sensor tegangan sesuai gambar 5 pada prinsipnya yaitu melakukan pencuplikan tegangan yang mengalir masuk ke sistem pengukuran, cara kerja sensor tegangan ini yaitu sensor tegangan diletakan paralel terhadap jaringan sumber. Rangkaian ini pada initinya terdiri dari transformator step down berfungsi menurunkan tegangan, rangkaian penyearah,filter kapasitor, rangkaian pembagi tegangan .

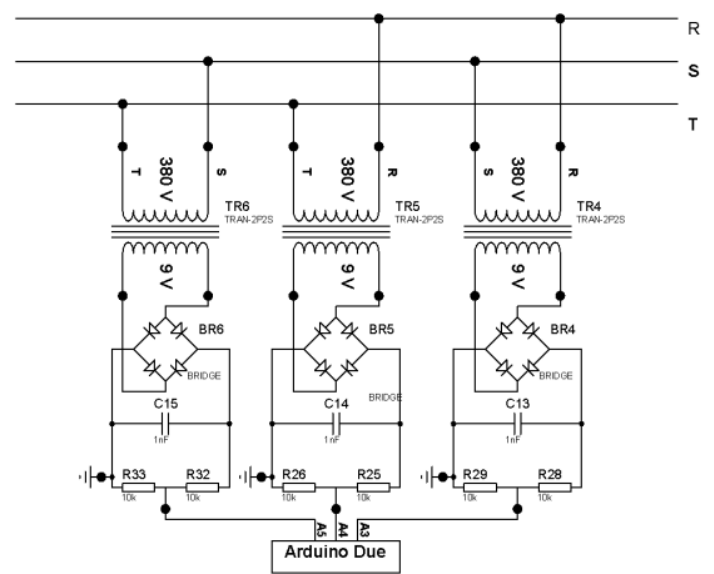

Gambar 5. Rangkaian Sensor Tegangan

\section{Rangkaian Sensor Arus}

Sensor arus ini mengunakan ACS712-5A sesuai gambar 6 yang memiliki kemampuan arus sampai 5 Ampere. Keluaran dari ACS ACS712-5A adalah tegangan DC. Perubahan yang dihasilkan dari keluaran sensor arus ACS ACS712-5A ini sangat kecil sekitar $185 \mathrm{mV}$ setiap perubahan 1 Ampere (sesuai data sheet).

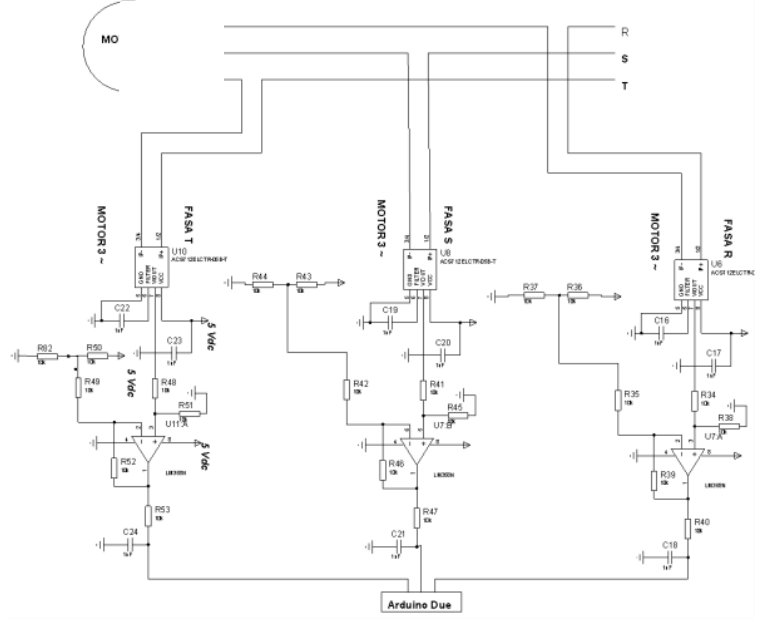

Gambar 6. Rangkaian Sensor Arus.

\section{Rangkaian Sensor Kecepatan}

Prinsip kerja dari sensor optocoupler sesuai gambar 7 yaitu dengan kombinasi LEDPhototransistor adalah Optocoupler yang terdiri dari sebuah komponen LED (Light Emitting Diode) yang memancarkan cahaya infra merah (IR LED) dan sebuah komponen semikonduktor yang peka terhadap cahaya (Phototransistor) sebagai bagian yang digunakan untuk mendeteksi cahaya infra merah yang dipancarkan oleh IR LED. 


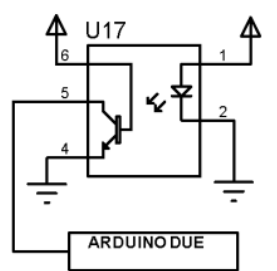

Gambar 7. Rangkaian Sensor optocoupler

\section{Rangkaian modul wifi ESP8266}

Modul wifi sesuai gambar 8 digunakan sebagai komunikasi data antara mikrokontroler ke basis data . modul wifi ini akan mengunggah data pembacaan dari sensor arus, sensor tegangan, dan sensor kecepatan yang telah diolah oleh mikrokontroler ke basis data menggunakan jaringan internet atau jaringan wifi yang tersedia.

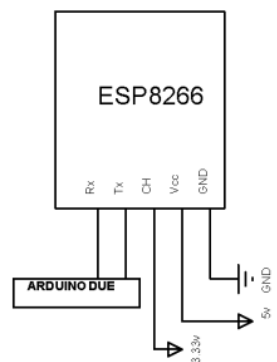

Gambar 8. Rangkaian modul wifi ESP8266

Modul wifi ini akan dihubungkan pada Arduino Due yang masuk pada pin digital I/O 14 dan pin digital I/O 15 .

\section{PENGUKURAN DAN PERCOBAAN}

Dalam melaksanakan suatu pengkuran dan pengujian alat, langkah pertam yang dilakukan adalah menyiapkan seluruh peralatan dan komponen yang akan dipasang untuk pengoperasian peralatan tersebut serta alat yang digunakan untuk mengukur dan menguji. Pengukuran dan pengujian hasil rancangan adalah bagian terpenting dari suatu perancangan. Percobaan dan pengukuran alat bertujuan untuk mendapatkan data yang benar pada titik-titik pengukuran dari alat yang telah dibuat, sehingga mempermudah menganalisis sistem dan memperbaiki kerusakan-kerusakan yang mungkin terjadi pada saat sistem bekerja.

\section{Hasil Perbandingan Pembacaan Tegangan Pada Alat Ukur Multimeter Dengan Pembacaan Pada Web}

Pengujian ini bertujuan untuk melihat apakah pembacaan pada tampilan web sudah sesuai dengan pembacaan pada alat ukur multimeter sesuai gambar 9. Pengujian ini akan menampilkan sampel pembacaan pada alat ukur dengan pembacaan pada tampilan web seperti tabel 1. d3elektro.com/m3f-mon $\times \square$

C $\triangle$ (i) d3elektro.com/m3f-monitoring/

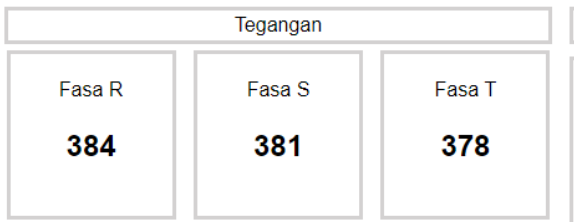

Gambar 9. Tampilan Pembacaan Tegangan antar fasa pada $W e b$

Tabel 1. Sampel Perbandingan Pembacaan Tegangan Pada Alat Ukur Dengan Tampilan Web Terhadap Tegangan Antar Fasa.

\begin{tabular}{|c|c|c|c|c|c|c|}
\hline \multirow[t]{2}{*}{ No } & \multicolumn{3}{|c|}{ Pembacaan Alat Ukur } & \multicolumn{3}{|c|}{$\begin{array}{c}\text { Pemabacaan Pada Tampilan } \\
\text { Web }\end{array}$} \\
\hline & $\begin{array}{c}V_{R S} \\
\text { (volt) }\end{array}$ & $\begin{array}{l}V_{S T} \\
\text { (volt) }\end{array}$ & $\begin{array}{c}V_{\text {TR }} \\
\text { (volt) }\end{array}$ & $\begin{array}{l}V_{R S} \\
\text { (volt) }\end{array}$ & $\begin{array}{c}V_{\text {ST }} \\
\text { (volt) }\end{array}$ & $\begin{array}{r}V_{\text {TR }} \\
\text { (volt) }\end{array}$ \\
\hline 1 & 370 & 380 & 373 & 373 & 381 & 374 \\
\hline 2 & 375 & 380 & 377 & 377 & 381 & 379 \\
\hline 3 & 374 & 380 & 375 & 377 & 381 & 377 \\
\hline 4 & 365 & 380 & 368 & 369 & 381 & 371 \\
\hline 5 & 380 & 380 & 382 & 384 & 381 & 378 \\
\hline
\end{tabular}

Pada tabel 1 tersebut bisa disimpulkan selisih antara pembacaan nilai tegangan antara alat ukur dengan tampilan pada web mempunya selisih $\pm 4 \mathrm{~V}$.

\section{Hasil Perbandingan Pembacaan Arus Pada Alat Ukur Dengan Pembacaan Pada Web}

Pengujian ini bertujuan untuk melihat apakah pembacaan pada tampilan web sudah sesuai dengan pembacaan pada alat ukur tang ampere. Pengujian ini akan menampilkan sampel pembacaan pada alat ukur dengan pembacaan pada tampilan web seperti tabel 2.

Tabel 2. Pembacaan Alat Ukur tang ampere Dengan Tampilan Web Terhadap Arus Fasa.

\begin{tabular}{|c|c|c|c|c|c|c|}
\hline \multirow{2}{*}{ No } & \multicolumn{3}{|c|}{$\begin{array}{c}\text { Pembacaan Alat } \\
\text { Ukur }\end{array}$} & \multicolumn{3}{|c|}{$\begin{array}{l}\text { Pemabacaan Pada } \\
\text { Tampilan Web }\end{array}$} \\
\hline & $\begin{array}{l}\text { IRS } \\
\text { (A) }\end{array}$ & $\begin{array}{l}\text { IST } \\
\text { (A) }\end{array}$ & $\begin{array}{l}\text { ITR } \\
\text { (A) }\end{array}$ & $\begin{array}{l}\text { IRS } \\
\text { (A) }\end{array}$ & $\begin{array}{l}\text { IST } \\
\text { (A) }\end{array}$ & $\begin{array}{l}\mathbf{I}_{\mathbf{T R}} \\
(\mathbf{A})\end{array}$ \\
\hline 1 & 0 & 0 & 0 & 0 & 0 & 0 \\
\hline 2 & 0,52 & 0,51 & 0,52 & 0,54 & 0,56 & 0,55 \\
\hline 3 & 0,71 & 0,70 & 0,73 & 0,74 & 0,71 & 0,77 \\
\hline 4 & 0,91 & 0,90 & 0,92 & 0,96 & 0,95 & 0,97 \\
\hline 5 & 0,9 & 1,0 & 0,9 & 0.86 & 1,14 & 0,87 \\
\hline
\end{tabular}


Pada tabel 2 tersebut bisa disimpulkan selisih pembacaan nilai tegangan antara alat ukur dengan tampilan pada web mempunyai $\pm 0,07 \mathrm{~A}$.

\section{Hasil Perbandingan Pembacaan Kecepatan Pada} Alat Ukur Tachometer Dengan Pembacaan Pada Web

Hasil Perbandingan Pembacaan Kecepatan Pada Alat Ukur Tachometer Dengan Pembacaan Pada Web ditunjukkan oleh tabel 3. Pengujian ini akan menampilkan sampel pembacaan pada alat ukur dengan pembacaan pada tampilan web seperti gambar 9.

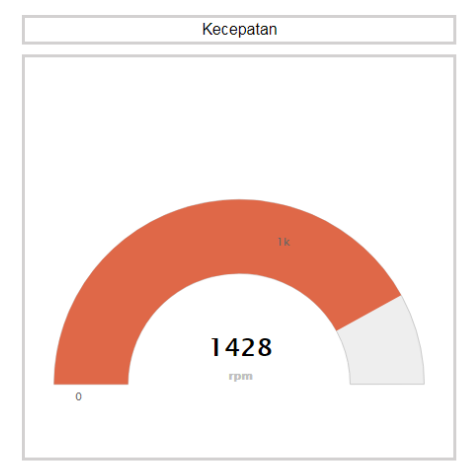

Gambar 9. Tampilan Pembacaan kecepatan pada Web

Tabel 3. Selisih Pembacaan Alat ukur Tachometer dengan tampilan pada web

\begin{tabular}{ccc}
\hline No & Tachometer $($ RPM $)$ & Web (RPM) \\
\hline 1 & 1450 & 1428 \\
\hline
\end{tabular}

Pembacaan Antara alat ukur tachometer dengan pembacaan web berbeda 22 RPM.

\section{Kesimpulan}

Setelah melakukan perancangan, pembuatan benda kerja dan percobaan ini, maka penyusun dapat memberikan simpulan sebagai berikut :

- Terjadi Perbedaan $\pm 0,24 \mathrm{~A}$ antara alat ukur Tang Ampere dengan pembacaan Pada web.

- Terjadi Perbedaan $\pm 4 \mathrm{~V}$ antara alat ukur Multimeter dengan pembacaan Pada Web.

- Kecepatan maksimum motor induksi 3 fasa tanpa beban berbeda 22Rpm antara alat ukur tachometer dengan tampilan web.

- Terdapat jeda waktu antara pembacaan sensor kecepatan pada web dengan pembacaan tachometer karena kecepatan internet yang dipakai kurang stabil.

- Pada tampilan tabel web harus di muat ulang apabila ingin melihat nilai pembacaan sensor terbaru.

- Arduino Due bisa mengirim data ke tampilan web selama modul wifi ESP8266 terkoneksi dengan jaringan internet.

\section{DAFTAR PUSTAKA}

1. Mahardika, Ferdina . 2016. Rancang Bangun Alat Memonitor Ketidakstabilan Daya Berbasis Arduino Mega 2560 Pada Motor Induksi 3 Fasa. Semarang : Laporan Tugas Akhir Teknik Elektro Universitas Diponegoro.

2. Girsang, Irma Sika. 2015. Perancangan Monitoring Jarak Jauh Ketinggian Air Pada Bendungan Menggunakan Sistem Android Via Jaringan Wi-Fi. Sumatera utara : Jurnal Ilmiah Ekstensi Fisika Instrumentasi FMIPA Universitas Sumatera Utara.

3. Santoso, Imam , Rizal Isnanto, R, Chaerodin, Achmad. 2008. Sistem Monitoring Suhu Berbasis Web Dengan Akuisisi Data Melalui Port Paralel PC. Semarang : Laporan Tugas Akhir Teknik Elektro Universitas Diponegoro.

4. Zuhal. 2000. Dasar Teknik Tenaka Listrik dan Elektronika Daya. Jakarta : Gramedia Pustaka Utama

5. Arduino. Arduino due. 12 Mei 2017 pukul 21.40.( https://www. arduino.cc/en /Main/ arduino BoardDue ).

6. Kho, Dickso . Pengertian dan prinsip kerja optocoupler. 12 Mei 2017 pukul 20.20. (http: //teknikelektronika .com / pengertianoptocoupler- fungsi- prinsip- kerja- optocoupler).

7. Quang, Sáng Bùi. Rotary Encoder Training Material. 12 mei 2017 pukul 22.15. (https: //www .slideshare.net /sangbuiquang3 /rotaryencoder -training- material).

8. Sugito, Tega.2016. Rancang Bangun Pengasutan Star Delta Pada Motor Induksi Tiga Fasa Berbasis Sensor Kecepatan Menggunakan Mikrokontroler Atmega 16 .Semarang : Laporan Tugas Akhir Teknik Elektro Universitas Diponegoro

9. Widiyaman, Tresna . Pengertian Modul Wifi ESPN8266. 11 Mei 2017 pukul 16.50. ( http: // www. Warriornux .com / pengertian - modul wifi - esp8266/).

10. Labradoc. ESP8266 WiFi Module Quick Start Guide. $\quad 10 \quad$ Mei pulul 17.40. (http://www.labradoc.com/i/follower/p/notesesp8266).

11. Prasetio, Andhi. 2012. Buku Pintar Pemrograman Web. Jakarta: Media K.

12. Hidayat, Rahmat. 2010. Cara Praktis Membangun Website Gratis. Jakarta: PT Elex Media Komputindo.

13. Fathansyah. 2012. Basis Data. Bandung: Informatika Bandung. 